\title{
TESTING AND ISOLATION STRATEGIES FOR THE VIBRATIONAL HAZARDS
}

\author{
Huang Wei ${ }^{1,2,3 *}$-Xu Jian ${ }^{1}$-Zhang Tong-yi ${ }^{1}$-Hu Ming-yi ${ }^{1}$-Qin Jing-wei ${ }^{1}$-Lan Ri-qing ${ }^{4}$ \\ ${ }^{1}$ Technology Research Center of Engineering Vibration Control, China IPPR International Engineering Co., Ltd, \\ Beijing 100089, China \\ ${ }^{2}$ Beijing Materials Handling Research Institute Co., Ltd, Beijing, P.R. China \\ ${ }^{3}$ Department of Civil Engineering, Tsinghua University, Beijing, P. R. China \\ ${ }^{4}$ Institute of Geophysics, China Earthquake Administration, Beijing 10081, China
}

\begin{tabular}{l} 
ARTICLE INFO \\
\hline Article history: \\
Received: 7.7 .2016$. \\
Received in revised form: 1.12 .2016$. \\
Accepted: 6.12 .2016$. \\
\hline Keywords: \\
vibration hazards \\
vibration test \\
vibration isolation \\
active vibration control \\
\hline
\end{tabular}

DOI: http://doi.org/10.30765/er.39.2.1

\begin{abstract}
:
In this paper, a test for investigating the vibrational hazards occurred in a modernized hospital was carried out, in which a lot of power equipment such as chilled water pumps and freezers, etc. were installed in the ground floor. The generated vibrations could be experienced on the upper floors including some medical precision room. Next, solation and active control strategies were proposed, and evidently the active control could improve the suppression a lot. This study illustrated that the great vibrational hazards could not be ignored anymore, and the followed resolution strategies for eliminating these vibrations seemed to be urgent. In tradition, the vibration isolations would not be involved in initial design for civil structures, but in fact this might lead to a severe problem to be addressed in the future, and this study could give inspiration for green building.
\end{abstract}

power equipment, and the whole structure is always under the vibration shadow. A test is a key measure for investigating the vibration level, of which people and engineers should pay attention to and some isolation strategies are also developed [5-7].

In this survey, a big, modernized and fully equipped hospital is investigated, in which a lot of power equipment is placed at the ground floor, and great vibrations can be perceived at the upper floors.

\section{Site investigation}

Figure 1 shows the site pictures from which are seen chilled water pumps and other power equipment as the main vibration source. In addition, there are basically no vibration isolation strategies performed here, and

\footnotetext{
* Corresponding author.

E-mail address: huanngwei@ippr.net
} 
the equipment is directly connected to the foundation which is not designed for a big volume of concrete foundation. Meantime, steel suspensions are used for supporting the pipes, but the vibrations are transmitted to the upper floors via this way.

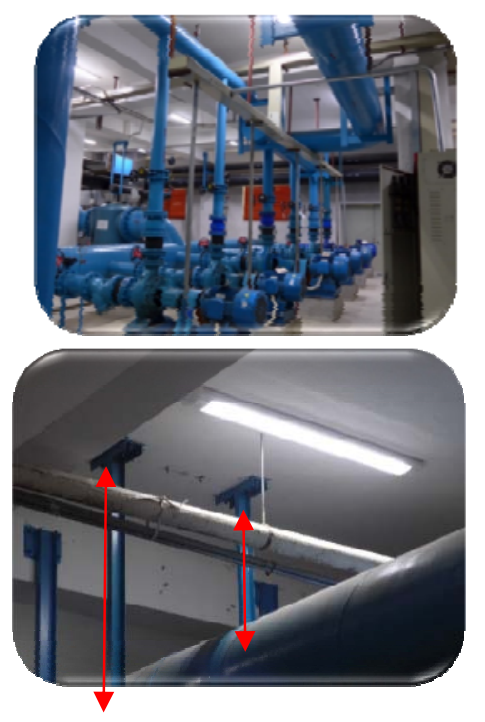

Figure 1. Site pictures.

The foundation is connected with the chilled water pumps only by a pair of steel shims (Fig. 2), and any other soft connections are not used. Apart from this, a single ball rubber isolator is inserted to the pipes which is aimed at suppressing the transmitted vibrations (Fig. 3). However, the whole ball is stretched to be a line and the original ellipsoid is completely deformed. From this a conclusion can be derived that this rubber does not play a good role in isolation.

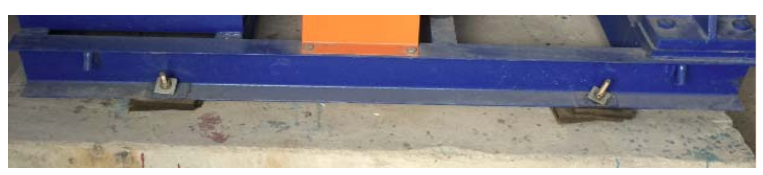

Figure 2. Connections of foundation and pumps.

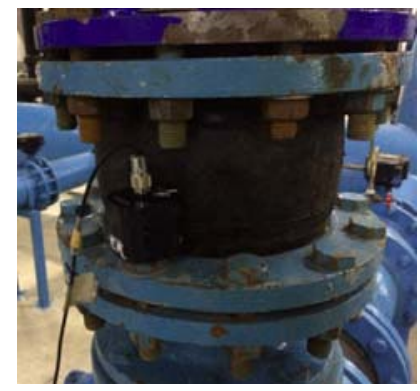

Figure 3. Stretched single ball rubber isolator.

\section{Site test}

\subsection{Vibration test for the chilled water pumps and affiliated area}

An arrangement of the vibration test points for the chilled water pumps are shown in Fig. 4 and described as following:

(1) Test points A and B: Identify the vibration transmission and attenuation via foundation.

(2) Test point C: Identify the vibration level of vibration source, i.e. the chilled water pumps.

(3) Test points D and E: Identify the suppressed level of single ball rubber isolator;

(4) Test points F and G: Identify the transmitted vibration from iron suspensions to the floor-1;

(5) Test points G and H: Identify and compare the vibration level of floor-1 and floor-2;

(6) Test I: Identify the influenced level of the surrounding and environmental vibrations to this project, such as traffic vibrations, etc.

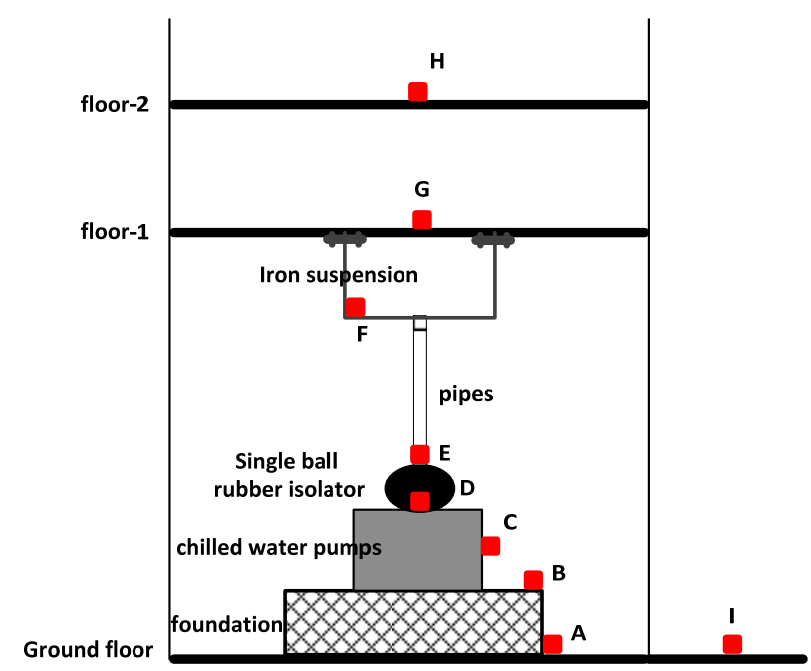

Figure 4. Arrangement of vibration test points for the chilled water pumps.

The site vibration test is shown in Fig. 5 and Fig. 6.
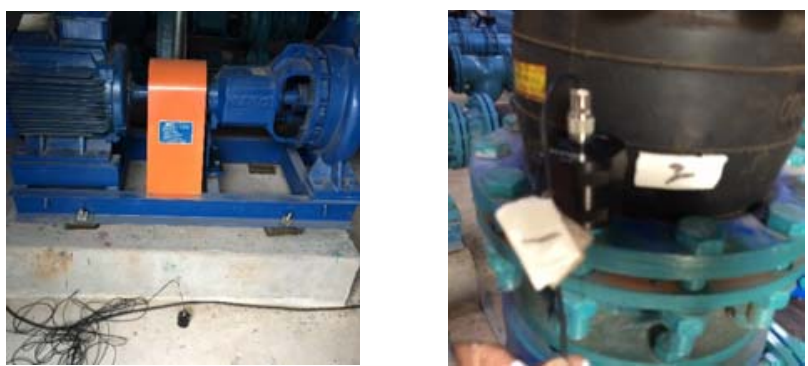

Figure 5. Site vibration test. 

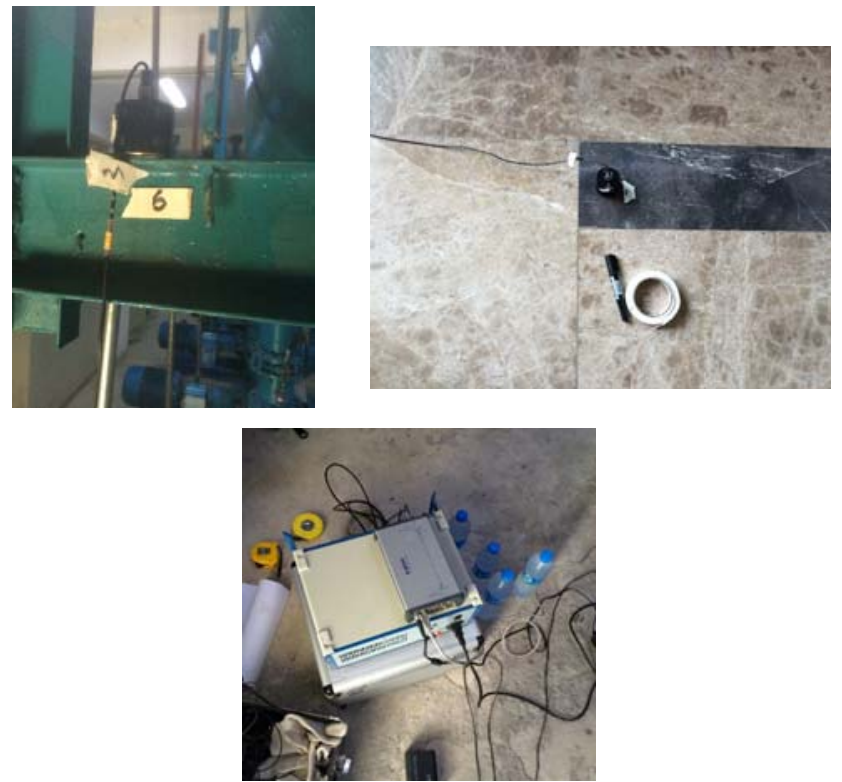

Figure 6. Site vibration test.

\subsection{Test results}

The vibration data collection and analysis for the ground floor (test point A), foundation (test point B) and the chilled water pumps as vibration source (test point C) is shown in Fig. 7, from which the vibrations are seen, almost not attenuating though they are transmitted from the foundation to the ground floor. In conclusion, the steel shims must be replaced by vibration isolators such as steel spring (Fig. 8), rubber, and so on. Meanwhile, a small volume of the concrete foundation does not work well and it must be redesigned. An embedded large volume of concrete foundation should be adopted here (Fig. 9).

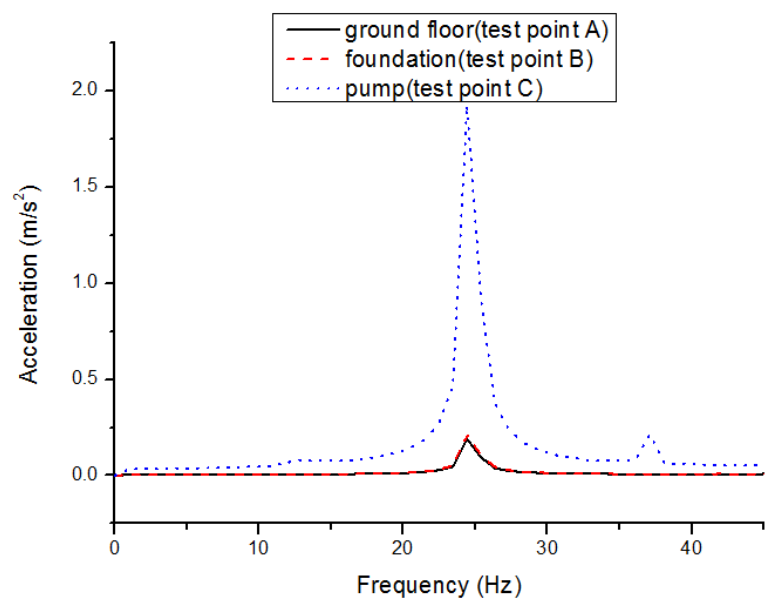

Figure 7. Vibration responses of the test points $A$, $B$ and $C$.

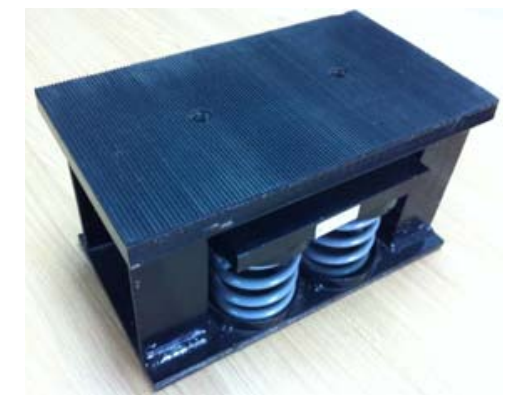

Figure 8. Steel spring.

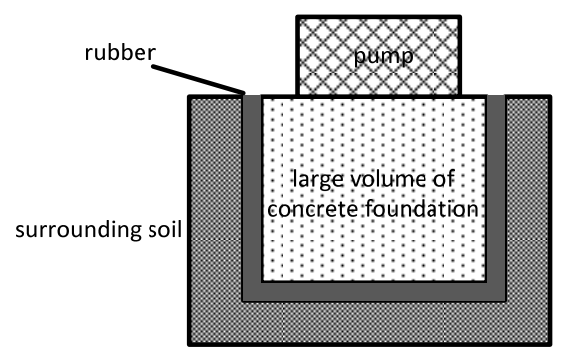

Figure 9. Embedded concrete foundation.

The vibration data collection and analysis for the chilled water pumps as vibration source (test point C), beneath the single ball rubber isolator (test point D), and above the single ball rubber isolator (test point E) is shown in Fig. 10. From this the suppression and isolation effect of a single ball rubber isolator is seen inconspicuous. On the contrary, the resonance is magnified. In conclusion, the stretched single ball rubber isolator should be replaced and the stretched condition must be adjusted. It can be redesigned in another way to become a double ball rubber isolator (Fig. 11).

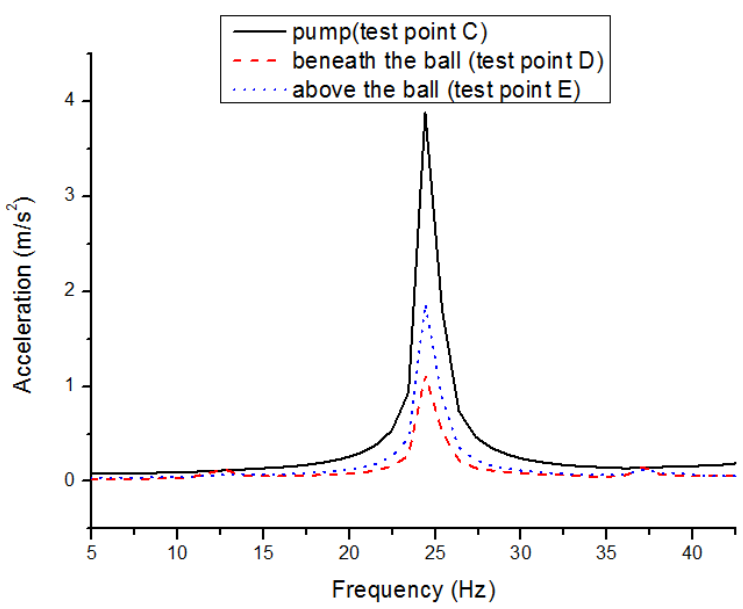

Figure 10. Vibration responses of the test points $C, D$ and $E$. 


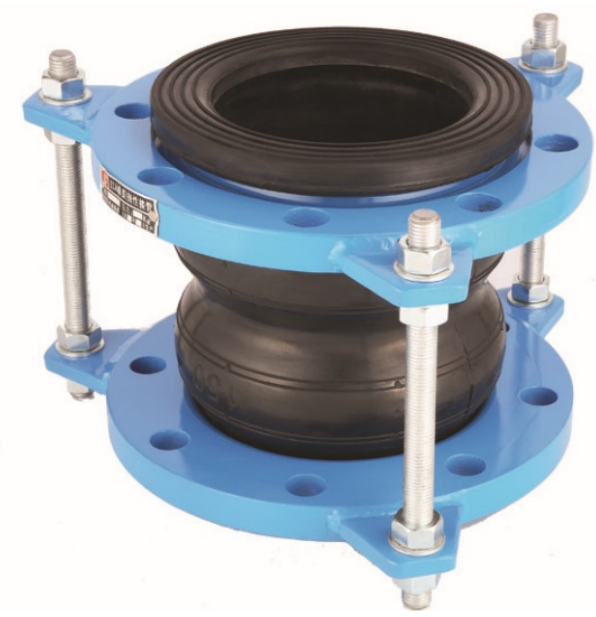

Figure 11. Double ball rubber isolator.

The vibration data collection and analysis for beneath the single ball rubber isolator (test point $D$ ), above the single ball rubber isolator (test point $\mathrm{E}$ ) and the iron suspension (test point F) is shown in Fig. 12., from which it is seen that the vibrations are transmitting constantly upwards. A conclusion can be indicated that the floor- 1 and the floor- 2 will be influenced. Accordingly, the iron suspensions should be changed into the support style with door bracket, and the connections between the bracket and ground floor can be inserted by the steel spring (Fig. 8), which is depicted in Fig. 13.

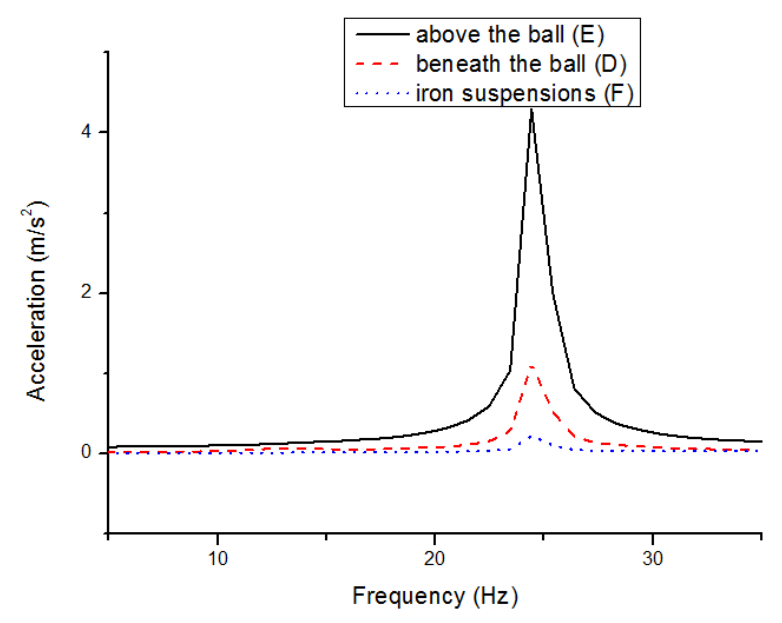

Figure 12. Vibration responses of the test points $D, E$ and $F$.

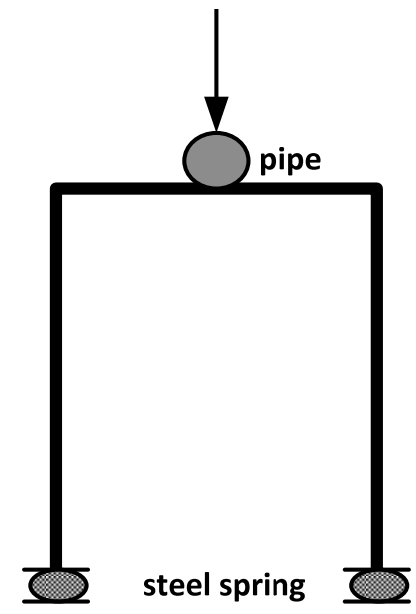

Figure 13. Door bracket support.

The vibration data collection and analysis for the iron suspension (test point F), the floor-1 (test point $\mathrm{G}$ ) and the floor-2 (test point $\mathrm{H}$ ) is shown in Fig. 14, from which it can be seen that the upper floors are influenced, and the vibrations by power equipment are transmitted inadvertently. The entire hospital, patients, and medical precision equipment are tending towards the vibrational hazards.

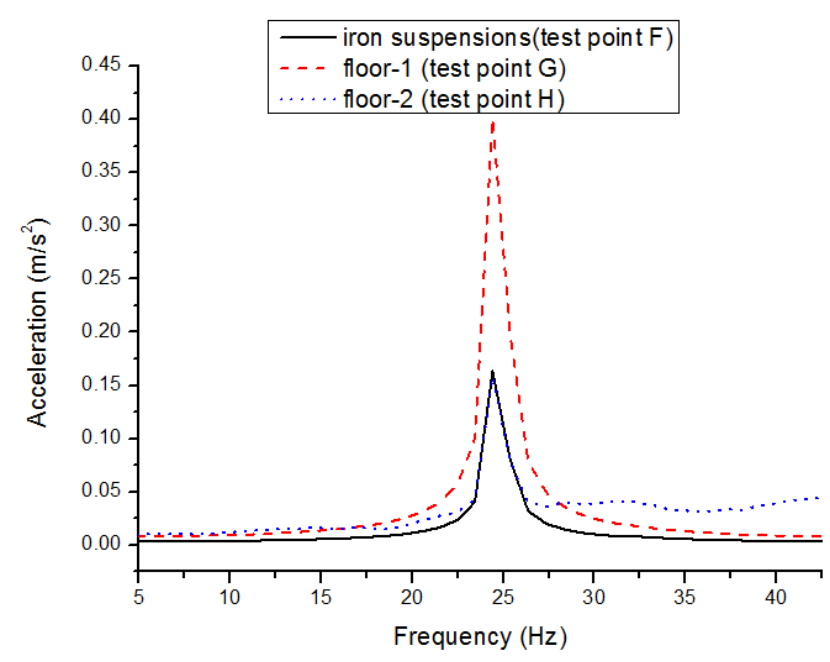

Figure 14. Vibration responses of the test points $F$, $G$ and $H$.

In addition, different chilled water pumps and freezers are tested for presenting the broad influence by vibrations, which is shown in Fig. 15 and Fig. 16. 


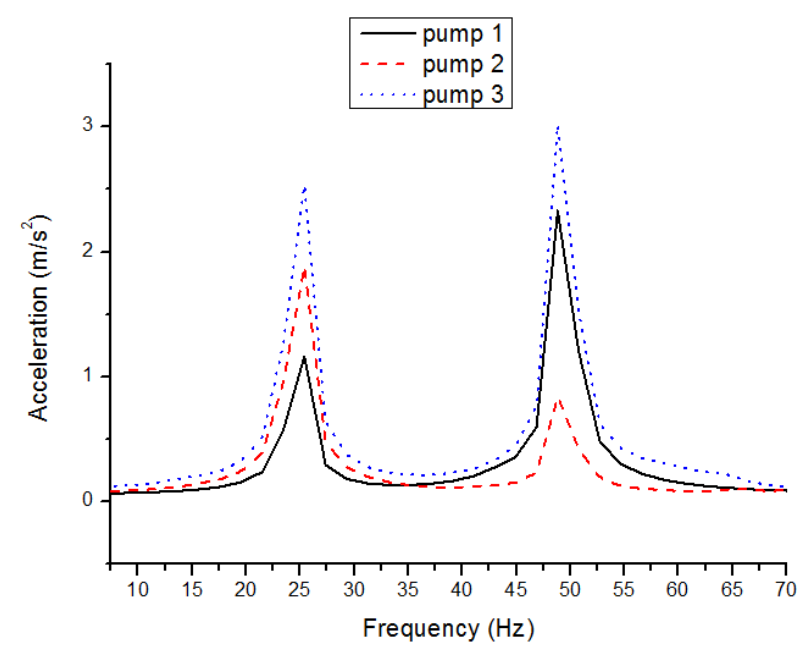

Figure 15. Vibration responses of different pumps.

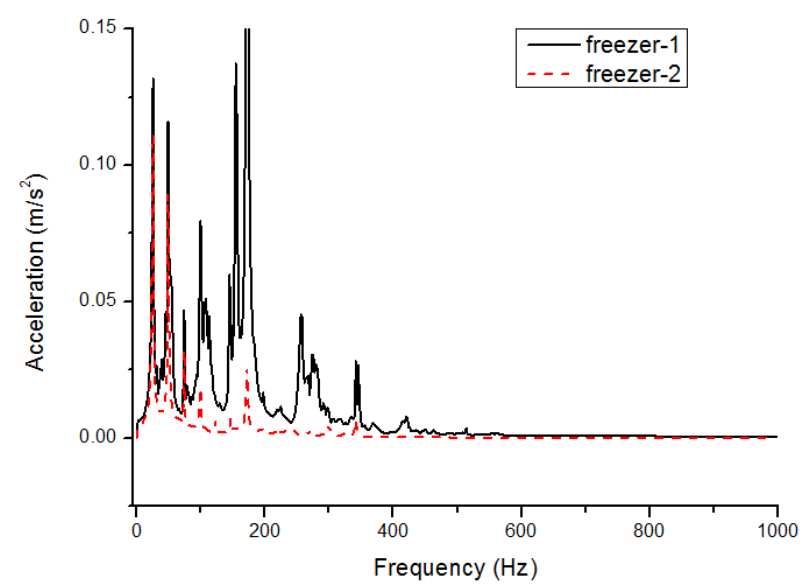

Figure 16. Vibration responses of different freezers.

\section{Active vibration control}

In the presentation of Fig. 8-9 and 11, which have given a practical steel spring, passive vibration isolations can be achieved for power equipment and pumps. Though passive strategies are easily to be performed and often carried out in practice, the passive design methods for low frequency vibration control are difficult and compromise between isolation performance and alignment of the supported machinery [8]. In order to overcome the shortcomings of the passive methods, active control methods have been the focus of recent research. The active control methods such as Sky-hook [9], LQR/LQG [10], and $H_{\infty}$ [11] have been presented in literature.

Active vibration control for power pumps is schematically depicted in Fig. 17, in which $m_{1}, k_{1}, c_{1}$ are respectively the mass, stiffness, and

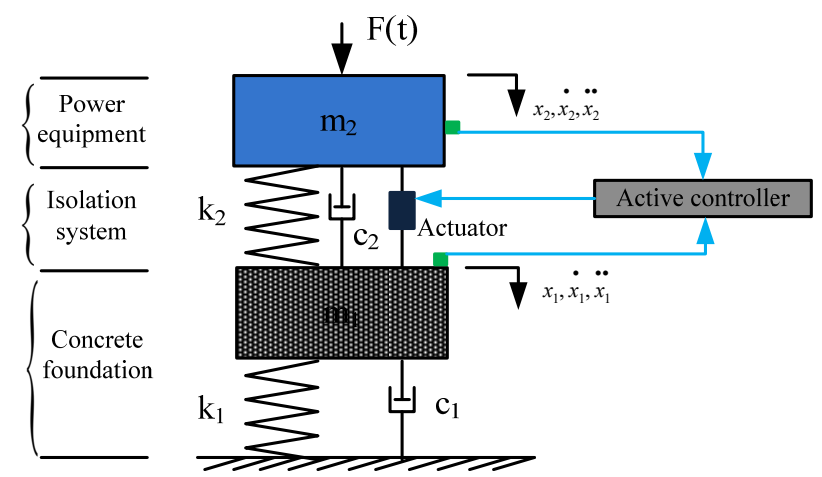

Figure 17. Active vibration control for power. equipment

damping of the concrete foundation; $k_{2}, c_{2}$ are respectively the stiffness and damping of isolation system; $m_{2}$ is the mass of power equipment; $F_{a}(t)$ is the active control force generated by actuator; $F(t)$ is the generated vibration load by the power equipment. The motion equations can be written as

$$
\left\{\begin{array}{l}
\mathrm{m}_{1} \ddot{x_{1}}+\mathrm{k}_{1} x_{1}+\mathrm{c}_{1} \dot{x_{1}}-\mathrm{c}_{2}\left(\dot{x_{2}}-\dot{x_{1}}\right)-\mathrm{k}_{2}\left(x_{2}-x_{1}\right)=F_{a}(t) \\
\ddot{\mathrm{m}_{2}} \ddot{x_{2}}+\mathrm{c}_{2}\left(\dot{x_{2}}-\dot{x_{1}}\right)+\mathrm{k}_{2}\left(x_{2}-x_{1}\right)=F(t)-F_{a}(t)
\end{array}\right.
$$

In the active control system, a series of state variables are provided here $z_{1}=x_{1} \quad z_{2}=x_{2}$, $z_{3}=\dot{x}_{1}, z_{4}=\dot{x}_{2}$ and a state vector is formulated as $z(t)=\left[z_{1}, z_{2}, z_{3}, z_{4}\right]^{T}$, and then the Eq. (1) can be rewritten as the state space form:

$$
\dot{z}=\mathrm{A} z+\mathrm{B}_{1} F_{\mathrm{d}}(t)+\mathrm{B}_{2} F_{a}(t)
$$

where

$$
\mathrm{A}=\left[\begin{array}{cccc}
0 & 0 & 1 & 0 \\
0 & 0 & 0 & 1 \\
-\frac{\mathrm{k}_{1}+\mathrm{k}_{2}}{\mathrm{~m}_{1}} & \frac{\mathrm{k}_{2}}{\mathrm{~m}_{1}} & -\frac{\mathrm{c}_{1}+\mathrm{c}_{2}}{\mathrm{~m}_{1}} & \frac{\mathrm{c}_{2}}{\mathrm{~m}_{1}} \\
\frac{\mathrm{k}_{2}}{\mathrm{~m}_{2}} & -\frac{\mathrm{k}_{2}}{\mathrm{~m}_{2}} & \frac{\mathrm{c}_{2}}{\mathrm{~m}_{2}} & -\frac{\mathrm{c}_{2}}{\mathrm{~m}_{2}}
\end{array}\right]
$$




$$
\mathrm{B}_{1}=\left[\begin{array}{c}
0 \\
0 \\
0 \\
\frac{1}{\mathrm{~m}_{2}}
\end{array}\right], \mathrm{B}_{2}=\left[\begin{array}{c}
0 \\
0 \\
\frac{1}{\mathrm{~m}_{1}} \\
-\frac{1}{\mathrm{~m}_{2}}
\end{array}\right]
$$

The control output is supposed as

$$
Y(t)=\mathrm{k}_{1} x_{1}+\mathrm{c}_{1} \dot{x_{1}}=\mathrm{k}_{1} z_{1}+\mathrm{c}_{1} z_{3}
$$

which indicates the transmitted force from the power equipment to the ground floor. In practice, a state observer with full state vector is generally difficult, and therefore an observer with a partial state vector is assumed here as

$$
y(t)=\left[\dot{x_{1}, \dot{x}_{2}}\right]^{\mathrm{T}}
$$

Eq. (4) can be rewritten as

$$
y(t)=\mathrm{C} z+\mathrm{d}_{1} F_{\mathrm{d}}(t)+\mathrm{d}_{2} F_{\mathrm{a}}(t)
$$

where

$$
\mathrm{C}=\left[\begin{array}{cccc}
0 & 0 & 1 & 0 \\
0 & 0 & 0 & 1
\end{array}\right] ; \mathrm{d}_{1}=\left[\begin{array}{l}
0 \\
0
\end{array}\right] ; \mathrm{d}_{2}=\left[\begin{array}{l}
0 \\
0
\end{array}\right]
$$

There must be input noise $\varepsilon_{1}(t)$ in Eq. (2) and measurement noise $\varepsilon_{2}(t)$ in Eq. (5), and then the state space equation and observation equation can be revised as

$$
\begin{gathered}
\dot{z}=\mathrm{A} z+\mathrm{B}_{1} F_{\mathrm{d}}(t)+\mathrm{B}_{2} F_{\mathrm{a}}(t)+\varepsilon_{1}(t) \\
y(t)=\mathrm{C} z+\mathrm{d}_{1} F_{\mathrm{d}}(t)+\mathrm{d}_{2} F_{\mathrm{a}}(t)+\varepsilon_{2}(t)
\end{gathered}
$$

where $\varepsilon_{1}(t)$ and $\varepsilon_{2}(t)$ are Gaussian random white noise with zero-mean value. In order to eliminate the negative influence of the presented noise to obtain a much better active control, the linear quadratic Gaussian (LQG) control method is adopted here, by which the active control force is generated as

$$
F_{\mathrm{a}}(t)=-K \hat{y}(t)
$$

where $K$ is the feedback gain in the LQG strategy, and $\hat{y}(t)$ is the estimation of $y(t)$.

A Kalman filter is constructed here for solving the estimation $\hat{y}(t)$, and the state space form is written as

$$
\left\{\begin{aligned}
\dot{\hat{z}}(t)= & \mathrm{A} \hat{z}(t)+\mathrm{B}_{1} F_{\mathrm{d}}(t)+\mathrm{B}_{2} F_{\mathrm{a}}(t)+ \\
& +K_{\mathrm{e}}[y(t)-\hat{y}(t)] \\
\hat{y}(t)= & \mathrm{C}_{2} \hat{z}(t)
\end{aligned}\right.
$$

where $\hat{z}(t)$ is the estimated state vector; $K_{e}$ is the gain of the Kalman filter; $C_{2}=$ $\operatorname{diag}([\operatorname{ones}(1,4)])$ and $\operatorname{diag}(\bullet)$ represents a diagonal matrix; ones $(m, n)$ generates a $m \times n$ unit matrix. A proposed LQG control with the Kalman filter is depicted in Fig. 18.

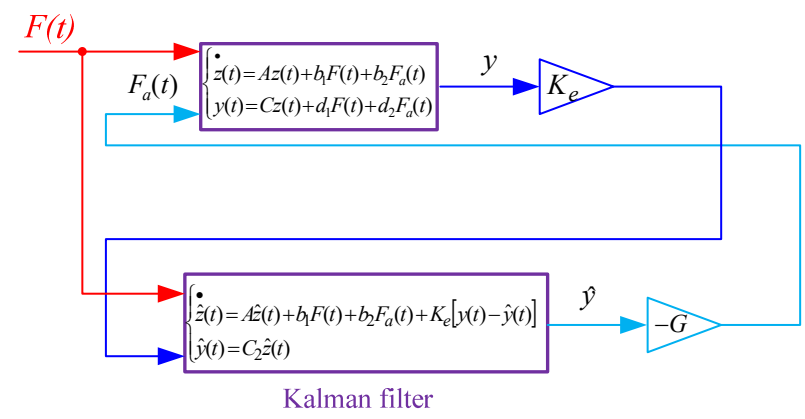

Figure 18. LQG active control with the Kalman filter for power equipment.

In this study, the LQG control is combined with PSO $[1,3]$ technique, and an optimized active controller is performed here, and the fitness function is defined as

$$
\left\|Y(t)-Y_{\text {desired }}(t)\right\|_{\infty}
$$

where $Y_{\text {desired }}(t)$ is the desired transmitted force from the power equipment to the ground floor, and it can be set as 0 in the optimization.

\section{Numerical studies}

In this survey, active vibration control for the chilled water pumps is performed here with a mass of $608 \mathrm{~kg}\left(m_{2}\right)$, and the amplitude of generated vibration load is $866 \mathrm{~N}$ and the disturbed frequency is $24.2 \mathrm{~Hz}$. By adopting the passive isolation strategies, the stiffness and damping of the steel 
spring are determined respectively as $7.2 \times 10^{4} \mathrm{~N} / \mathrm{m}\left(k_{2}\right)$ and $9242 \mathrm{~N} / \mathrm{m} \cdot \mathrm{s}^{-1}\left(c_{2}\right)$. The mass, stiffness and damping of the large volume of concrete foundation are determined respectively as $918 \mathrm{~kg}\left(m_{1}\right), 2.5 \times 10^{5} \mathrm{~N} / \mathrm{m}\left(\mathrm{k}_{1}\right)$ and $100 \mathrm{~N} / \mathrm{m} \cdot \mathrm{s}\left(\mathrm{c}_{1}\right)$. Parameters configuration of the PSO algorithm is provided with the population size of particles $=$ 100, maximum iteration number $=200, C_{1}=2$, $C_{2}=1, \omega=0.99^{T}$ ( $T$ is the iterative number) [12]. A constrained condition for optimizing the weight matrix of the LQG controller is assumed arbitrarily as

$$
\begin{aligned}
& {\left[1 \times 10^{-7}, 1 \times 10^{-7}, 1 \times 10^{-7}, 1 \times 10^{-7}, 1 \times 10^{-7}\right] \sim} \\
& \quad \sim\left[1 \times 10^{7}, 1 \times 10^{7}, 1 \times 10^{7}, 1 \times 10^{7}, 1\right]
\end{aligned}
$$

Fitness convergence of this optimization is shown in Fig. 19, and the obtained gbest solution is

$$
\begin{aligned}
& Q=\operatorname{diag}\left[\begin{array}{llll}
7.541 & 5.535 & 9.028 & 3.016
\end{array}\right] \times 10^{6}, \\
& R=8.415 \times 10^{-4}
\end{aligned}
$$

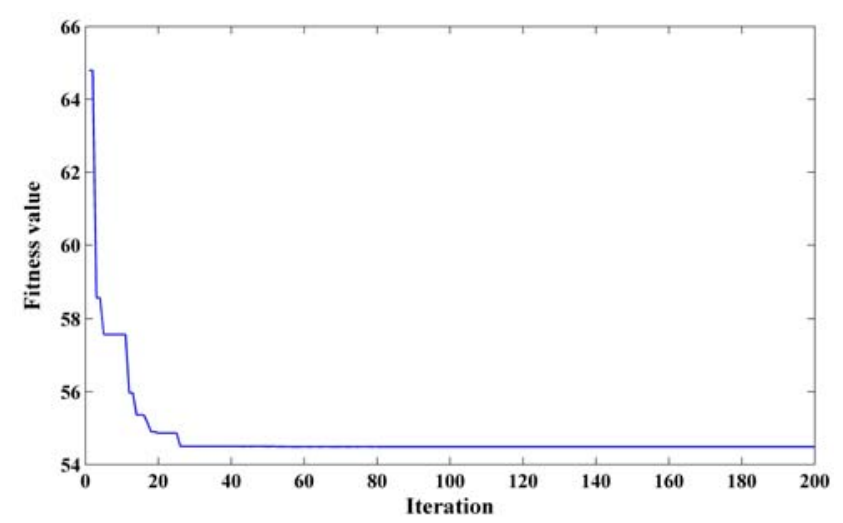

Figure 19. Fitness convergence.

By using this active vibration control, the suppressed transmitted force from the pumps to the ground floor is shown in Fig. 20. From this it can be seen the peak suppression effect of transmitted force which has been promoted by using active control and compared with the passive isolations.

\section{Conclusion}

In this paper, a survey for vibrational hazards by power equipment in a hospital is carried out, and the vibrations influencing the entire structure are presented. vibrations influencing the entire structure

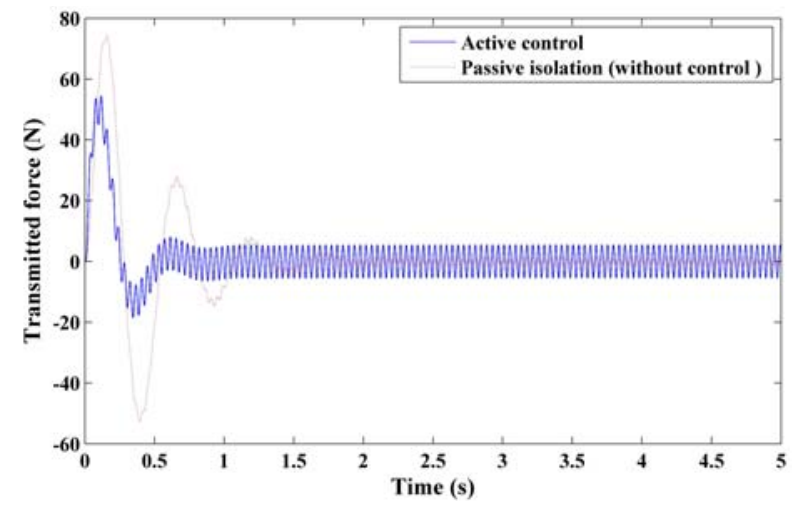

Figure 20. Transmitted force for comparison.

Are presented. After investigation, the isolation strategies are performed and optimal active vibration control with the PSO technique is further discussed. The numerical results confirm better suppression of the active control than the passive methods.

In fact, the presented topic in this paper is often ignored in our practice, and seismic vibrations are always concentrated on. However, in our modern life, vibrations must be taken into account when the initial structural design is performed. A new branch of green building can be pushed towards. We also appeal that the vibrational hazards must be eliminated like other pollutions from our life.

\section{Acknowledgments}

This research is completely supported by National Key Research and Development Program "Research on Vibration Control Technology for Established Industrial Building Structures", which is sponsored by the Ministry of Science and Technology of the P. R. China and the Grant No. is 2016YFC0701302. Meantime, it is also supported by Major Technology Project of China National Machinery Industry Corporation (SINOMACH), research and application of key technologies for industrial environment monitoring, early warning and intelligent vibration control (SINOMAST-ZDZX2017-05)'. It is also launched as a preparation for the revising work of 'Code for design of vibration isolation' (national code of P. R. China).

A team of colleagues in China National Machinery Industry Corporation (SINOMACH) and Technology Research Center of Engineering Vibration Control (EVCC) in China IPPR International Engineering Co., Ltd (IPPR) are gratefully acknowledged. 


\section{References}

[1] Huang, W., Xu, J., Zhu, D., et al: Semi-active Vibration Control Using a Magneto Rheological (MR) Damper with Particle Swarm Optimization, Arabian Journal for Science and Engineering, 40, (2015)3: 747-762.

[2] Huang, W., Xu, J., Zhu, D., et al.: Parameter configuration of composite vibration isolation system using power flow and MOPSO technique, Mechanics \& Industry, 7(2016), 5: 501.

[3] Huang, W., Xu, J., Zhu, D., et al.: Multiobjective optimization of parameters and location of passive vibration isolation system excited by clamped thin plate foundation, Engineering Review, 36(2016), 1: 19-27.

[4] Takamatsu, M., Futatsuka, M., Sakurai, T., et al.: A study of the extent and scope of local vibration hazards in Japan, Industrial health, 20(1982), 3: 177-190.

[5] Veal, D., Hughes, B., Wagner, M.: Reference excitation unit for micro-vibration test facilities, 12th European Conference on Spacecraft Structures, Materials and Environmental Testing. 2012, 691: 187.

[6] Joo, S. J., Park, B., Kim, D. H., et al.: Investigation of multilayer printed circuit board (PCB) film warpage using viscoelastic properties measured by a vibration test, Journal of Micromechanics and Microengineering, 25(2015), 3: 035021.

[7] Wei, F. S.: Analytical dynamic model improvement using vibration test data, AIAA journal, 28(1990), 1: 175-177.

[8] Daley, S., Hätönen, J., Owens, D. H.: Active vibration isolation in a "smart spring" mount using a repetitive control approach, Control Engineering Practice, 14(2006), 9: 991-997.

[9] Karnopp, D., Crosby, M. J., Harwood, R. A.: Vibration control using semi-active force generators, Journal of Engineering for Industry, 96(1974), 2: 619-626.

[10] Hrovat, D.: Applications of optimal control to advanced automotive suspension design, Journal of Dynamic Systems, Measurement, and Control, 115(1993), 2B: 328-342.

[11] Du, H., Sze, K. Y., Lam, J.: Semi-active $H_{\infty}$ control of vehicle suspension with magnetorheological dampers, Journal of Sound and Vibration, 283(2005), 3: 981-996.

[12] Farshidianfar, A., Saghafi, A., Kalami, S. M., et al.: Active vibration isolation of machinery and sensitive equipment using $H_{\infty}$ control criterion and particle swarm optimization method, Meccanica, 47(2012), 2: 437-453. 